\title{
Treatment Problem of the Upper Aero Digestive Tract's Cancers at the Regional Hospital Center of Ziguinchor in Southern Senegal
}

\author{
Ndadi Tchiengang K Junie ${ }^{1 *}$, Senghor Fabrice², Randriamalala Nirina Andry ${ }^{3}$, Diallo Mamadou Talibé4, DIOM Siga \\ Evelyne $^{1,}$ Diallo Bay Karim ${ }^{5}$
}

${ }^{1}$ ENT department, Peace Hospital of Ziguinchor, Senegal

${ }^{2}$ Anatomy and pathological cytology laboratory, Assane Seck University, Senegal

${ }^{3}$ ENT department, Antananarivo hospital center, Madagascar

${ }^{4}$ ENT department, Regional hospital center of Ziguinchor, Senegal

${ }^{5}$ ENT department, Albert Royer children Hospital, Senegal

Submission: January 20, 2021; Published: February 09, 2021

*Corresponding author: Ndadi Tchiengang K Junie, ENT Department, Peace Hospital, Ziguinchor, Senegal

\section{Abstract}

Introduction: Cancers of the upper aero digestive tract (UADT) regroup tumors of the oral cavity, of the three stages of the pharynx (cavum, oropharynx, hypopharynx), of the larynx and of the facial mass. ENT tumor pathology is a public health problem and has specific treatment features due to the specific features of the disease and the patient. The aim of this study was to highlight the difficulties in diagnosing and UADT's cancer treatment in Ziguinchor, a town in the south of Senegal.

Materials and methods: This were a retrospective study in the ENT department of the regional hospital of Ziguinchor over a period of 10 years, from January 1st, 2010 to December 31st , 2020. All patients with UADT's cancers with histological confirmation during this period were included in our study.

Results: Out of 87 patients with histologically confirmed UADT's cancer, there were 56 men and 31 women, for a sex ratio of 1.80 . The most affected social stratum was housewives, i.e., $27.58 \%$. Lesions were either exceeded or inoperable in $63.21 \%$ (of the patients. The time to pathology results was on average 1 month with extremes of 04 days and 10 months. Fifty-nine-point seventy-seven percent of the patients had surgery.

Conclusion: The treatment of UADT's cancers in Ziguinchor requires intervention by the state and partners between an increasingly poor patient (from diagnosis to treatment) and increasingly refined therapies and therefore more and more expensive.

Keywords: Cancer; UADT; Ziguinchor; Senegal

\section{Introduction}

Cancers of the upper aero digestive tract (UADT) regroup tumors of the oral cavity, of the three stages of the pharynx (cavum, oropharynx, hypopharynx), of the larynx and of the facial massif [1]. Each year, around 650,000 new cases are diagnosed worldwide [2]. They are recurrent in Europe and particularly in France where their annual incidence is the fifth most frequent cancer [3]. In Senegal and specifically in the Dakar region, studies carried out in 2010 revealed the pharynx as the third main organ affected by cancer after the breast and the uterus [4]. ENT tumor pathology thus constitutes a public health problem. It also has specific treatment characteristics due, on the one hand, to the specific features of the disease (damage to important organs affecting social relations, speech, and food) and, on the other hand, to the patient (frequency of alcohol-smoking dependence and psychosocial problems) [1]. If major progress in the face and neck cancer's treatment has been made over the last decade [5], Senegal and specifically the city of Ziguinchor (approximately $455 \mathrm{~km}$ from Dakar, the capital of Senegal) still present considerable difficulties. The aim of this study was to underline the difficulties in diagnosing and treating cancers in Ziguinchor, in the south of Senegal. 


\section{Global Journal of Otolaryngology}

\section{Patients and Method}

We conducted a retrospective study in the ENT department of the Ziguinchor regional hospital over a period of 10 years, from January $1^{\text {st }}, 2010$ to December $31^{\text {st }}, 2020$. All patients, regardless of age, with UADT cancers with histological confirmation during the study period were included. The information was collected from the medical records of patients meeting our selection criteria, hospitalization records, registers of operating reports and ENT department records retained for this research. The variables studied were grouped into epidemiological, clinical, diagnostic, and therapeutic parameters. It was about sex, socio-professional level, geographic origin, number of exceeded or inoperable lesions, time to consultations, time to obtain anatomopathological results, patient survival, number of patients with histological confirmation and the type of treatment received. Thus, the data collected was analyzed using the software Epi info 7.2.2.6 and Microsoft Excel 2016. The data were entered and processed using the Microsoft Word and Excel software from the 2016 office pack.

\section{Results}

\section{Epidemiological data}

Out of 87 patients with histologically confirmed UADT cancer, there were 56 men and 31 women, for a sex ratio of 1.80 . The most affected social stratum were housewives, i.e., $27.58 \%(\mathrm{~N}=$ 24) (Table I). The patients came mainly from the city of Ziguinchor $(\mathrm{N}=45)$ (Figure 1).

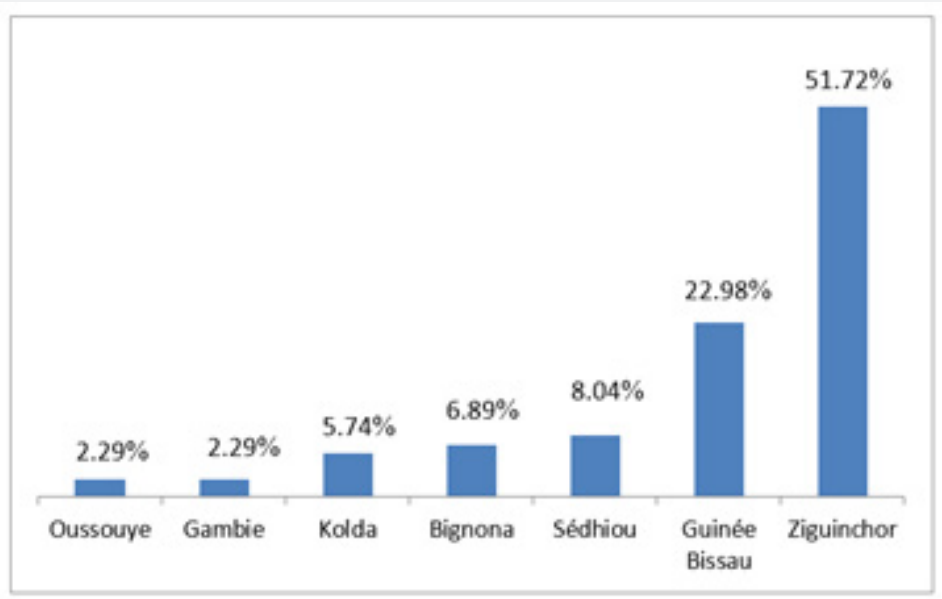

Figure 1: Distribution of patients by geographic origin.

\section{Clinical data}

The consultation period was on average 2 years with extremes of 15 days and 17 years. Lesions were either exceeded or inoperable in $63.21 \%$ (of the patients $(\mathrm{N}=55)$. With a followup of two years, 04 patients were alive after radiotherapy. Four years later, the cancer recurred in 02 patients (Figure 2).

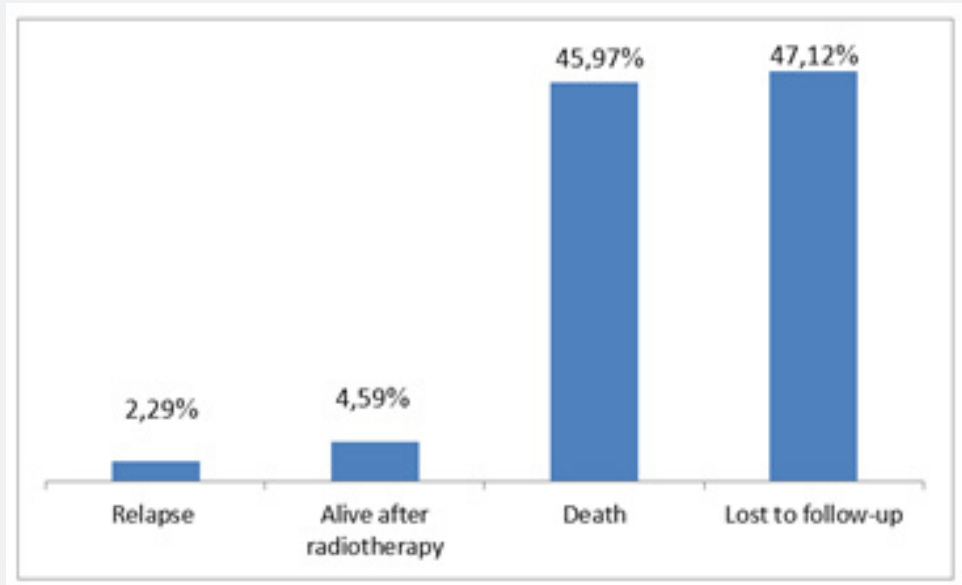

Figure 2: Distribution of patients according to survival. 


\section{Diagnostic data}

Out of 151 suspected cancer, 87 were confirmed by histology, i.e., $57.61 \%$. The time taken to obtain anatomopathological results was on average 1 month with extremes of 04 days and 10 months.

\section{Therapeutic data}

Fifty-two $(\mathrm{N}=52)$ of our patients underwent surgery (Figure $3)$.

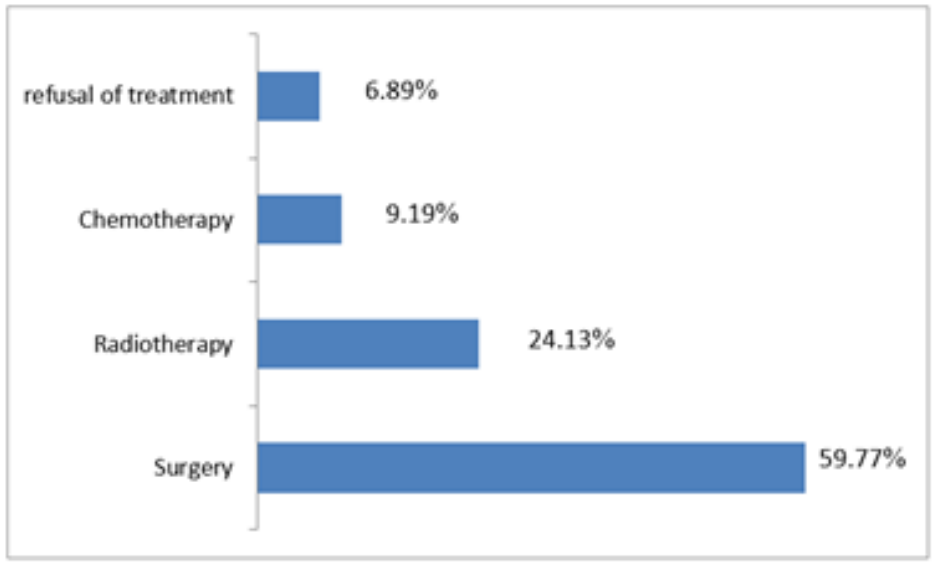

Figure 3: Distribution of patients according to treatment

Table 1: Distribution of patients according to socio-professional level.

\begin{tabular}{|c|c|c|}
\hline Profession & Number & Frequency \\
\hline Officials & 14 & $16.09 \%$ \\
\hline Cultivators & 9 & $10.34 \%$ \\
\hline Craftsmen & 8 & $9.19 \%$ \\
\hline Drivers & 3 & $3.44 \%$ \\
\hline Cook(S) & 3 & $3.44 \%$ \\
\hline Pupils & 7 & $8.04 \%$ \\
\hline Breeders & 5 & $5.74 \%$ \\
\hline Sportsmen & 3 & $3.44 \%$ \\
\hline Religious & 5 & $5.74 \%$ \\
\hline Street vendors & 3 & $3.44 \%$ \\
\hline Housewives & 24 & $27.58 \%$ \\
\hline Fishermen & 3 & $3.44 \%$ \\
\hline Total & 87 & $100.00 \%$ \\
\hline
\end{tabular}

\section{Discussion}

\section{Epidemiological data}

In our study, we obtained a sex ratio of 1.8 for a predominance of men. The male predominance is reported by several authors because of the heavy consumption of tobacco and alcohol among men [6]. In France, the UADT cancers were fourth in men and tenth in women [7]. An African study on breast cancer showed that the most affected social stratum was mostly patients of low socioeconomic level [8]. In the field of ENT cancerology, most cancers affect a population often composed of employees, workers, and unemployed individuals [9]. In Ziguinchor, housewives were the social stratum most affected by cancer. More than half of the patients in our study were from the city of Ziguinchor because our study setting was in the city of Ziguinchor and the Ziguinchor regional hospital is one of the first referral hospitals in the south of Senegal.

\section{Clinical data}

The consultation time is defined as the time between the appearance of the first symptom and the first consultation with a healthcare professional [6]. In northern countries such as New Zealand, Canada, Denmark, this period ranges from 46 days to 4 months [6]. In a Malagasy study of UADT cancers, the author stated that it was about 7 months long on average [6]. In our study, it was even longer. A long consultation period delays the diagnosis, so tumor development is not controlled [10]. The diagnosis is most often made at a late stage in patients who are sometimes negligent because the evolution is essentially loco regional cervicofacial, and it is at an already advanced stage that there will be a functional impact on their swallowing and breathing functions [3]. Lesions were either exceeded or inoperable in more than half of our patients. In our context, the regional hospital center of Ziguinchor occupies a strategic place in the south of Senegal. It has a high technical platform compared to other hospital structures in the region.

Patients from remote towns in the region are forced to go there. Geographic inaccessibility and financial difficulties are therefore potential factors for delayed diagnosis. The analysis of survival rates is made difficult by the great heterogeneity of UADT 
tumors, by the importance of lymphophilia, by the complexity of the treatments implemented and the difficulty of carrying out randomized trials that are extended in the time. For all stages and locations combined, survival remains on average between 30 and $40 \%$ at 5 years [3]. Rakotoarivony, in his study on mouth and pharynx cancers stated that survival is very low [11]. The death rate in his study was $21.4 \%$ and the loss to follow-up rate was estimated at 75\%. In our study, the high death rates $45.97 \%$ and lost to follow-up $47.12 \%$ could be related to the financial and logistical difficulties of the patients. Allison attributes this high death rate to the delay of the consultations [12].

Regarding relapses, nearly $90 \%$ occur in the first two years after initial treatment [13]. Beyond the period of the first three years during which attention must be paid to the risk of relapse, the surveillance should focus on the detection of a second location whose risk persists over time [14]. In our study, we recorded relapse in 02 patients, four years later.

\section{Diagnostic data}

UADT cancers are initially pauci-symptomatic. The unilateral nature and / or the persistence of clinical signs are suggestive and should systematically raise the suspicion of cancer [4]. The definitive diagnosis is anatomopathological and allows to give the histological type [13]. Rakotoarivony [11] considered that the anatomopathological result was a sine qua non for its study on oral cavity and pharynx cancers. In our study, we could only confirm $57.61 \%$ of cancers to the histology and the time to obtain pathological results was long. This is because during the first 8 years of our study, there was no anatomopathology laboratory in Ziguinchor. The patients then had to go to Dakar, the capital of the country, to one of the laboratories, to drop off their biopsies or surgical documents. Indeed, Ziguinchor is located about $455 \mathrm{~km}$ from Dakar. This major logistical difficulty was a major handicap in the diagnosis of cancers. Potential factors, related to the patient and the health system, delay the diagnosis of UADT cancer [6]. In Ziguinchor, it was about financial, geographic, and logistical difficulties.

\section{Therapeutic data}

Depending on the location of the tumor, its stage and the general condition of the patient, the first-line treatment modalities are surgery, radiotherapy, conventional chemotherapy, and targeted therapies [15]. In our study, the low rate of patients having undergone chemotherapy or radiotherapy could be due to the remoteness of the oncology and radiotherapy centers located in the Dakar region. Patients must go there for treatment. Some patients express reservations because of the distance and the fact that they do not know the city of Dakar and have no family there. In Africa, the number of cancer patients is increasing as the cost of treating the disease increases [16]. Chemotherapy is practiced with protocols ranging from the least expensive to the most expensive with costs ranging from 60,000 FCFA (100 Euros) to more than 400,000 FCFA (600 Euros) per treatment [17]. Apart from the exorbitant costs of the products, their availability in the market is also a problem; ruptures are frequent, requiring interruptions or postponements of treatments. This irregularity in chemotherapy is known as tumor cell growth factor or therapeutic escape. As radiotherapy is currently practiced in Senegal by the only existing cancer center in the Dakar region, this poses the problem of overloading this unit, thus increasing treatment times with still no cost negligible (150,000 FCFA or around 200 Euros) [17]. The cost of treatment is a big handicap for most of our lowincome patients. In Rakotoarivony's study, one case refused to seek treatment and requested discharge from hospital against medical advice [11]. In our study we were confronted with $6.89 \%$ of patients who had refused any treatment. Confusion, ignorance, habits, and customs could be the reason.

\section{Conclusion}

The UADT cancers treatment in Ziguinchor requires the intervention of the State and partners between an increasingly poor patient (from diagnosis to treatment), increasingly refined therapeutic treatments and therefore more and more expensive. Cancer treatment is multisectoral. The journey of a patient with UADT cancer in Ziguinchor is tedious. He started from the ENT department in the anatomopathology laboratory, then at the chemotherapy or radiotherapy center in Dakar and finally returned to Ziguinchor. This study enabled us to identify the problems encountered in the UADT cancers' treatment in Ziguinchor. It reminds us of the large gaps to be filled in the awareness of the populations, the training, and the equipment of the structures to be able to make the diagnoses in time, to lead a complete treatment on the spot without travelling and finally improve the psycho-social support for patients. Achieving these goals necessarily requires improving the availability and accessibility of anti-cancer drugs.

\section{References}

1. Oncobretagne (2015) Cancer ORL. Theseaurus.

2. Maliha S, Stefan O, Schoenberg, Haneen Sadick (2012) Current oncologic concepts and emerging techniques for imaging of head and neck squamous cell. GMS Curr Top Otorhinolaryngol Head Neck Surg 11: $1-24$.

3. Poissonnet G, Benezery K, Peyrade F (2007) ENT cancers: the main therapeutic principles. Press Med 36: 1634-1642.

4. KJ Ndadi Tchiengang, A Thioubou, F Senghor (2020) Diagnostic wandering about a case of squamous cell carcinoma of the hypopharynx. Jaccr Africa 4(3): 632-633.

5. Kolb F, Julieron M (2005) reconstructive surgery in ENT oncology: main methods and indications. Cancer Radiother 9: 16-30.

6. N E Randriamanovontsoa, N R E Hasiniatsy, M Razakanaivo (2015) Epidemiological and clinical characteristics ofthe upper aerodigestive tract's cancer at the Oncology Service of CHUA / JRA from 2008 to 2012. La Revue Médicale de Madagascar 5(3): 611-615.

7. Auperin A, Melkane A, Luce D (2011) Epidemiology of cancers of the upper aero-digestive tract. Oncologist Letter 20: 102-106. 
8. Coulibaly, Oumou Judith (2002) Problematic of the breast cancer treatment: about 255 cases collected in Abidjan. Doctoral thesis in medicine, UFR des Sciences Médicales Abidjan, Virtual Library-MESRS

9. Emmanuel Babin, Guillaume Grandazzi (2009) Quality of life of ENT cancer patients. The Letter of ENT and Head and Neck Surgery 316.

10. Morelatto RA, Herrera MC, Fernandez EN, A G Corball, S A López de Blanc (2007). Diagnostic delay of oral squamous cell carcinoma in two diagnosis centers in Cordoba Argentina. J Oral Pathol Med 36: 405-408.

11. A E Rakotoarivony, R A Rakotoarison, F A Razanakoto (2014) Malignant tumors of the oral cavity and pharynx: an 11-year study at the Soavinandriana Hospital Center, Antananarivo. The Medical survey of Madagascar 4(2)

12. Allison P (2004) Epidemiology and etiology of mouth and pharynx cancers in Canada and Quebec. J Dent 48: 6-11.
13. Haute Autorité de Santé (2009) Cancer of the upper aerodigestive tract. National Cancer Institute 36.

14. Cancers of the upper aerodigestive tract in 10 key points (2020) Available on Collection Tools for the practice of general practitioners - From diagnosis to follow-up.

15. Cancers of the upper aerodigestive tract, from diagnosis to followup (2018) Available on Collection Tools for the practice of general practitioners - From diagnosis to follow-up.

16. Guide to Cancer Research in Africa (2013) WHO / AFRO Library.

17. Serigne Modou Kane Gueye, Mamour Gueye, Sophie Aminata Coulbary Alassane Diouf, Jean Charles Moreau (2016) The issue of breast cancer treament in Senegal: a transversal approach. Pan African Medical Journal 25(3): 3785.

\section{Your next submission with Juniper Publishers will reach you the below assets}

- Quality Editorial service

- Swift Peer Review

- Reprints availability

- E-prints Service

- Manuscript Podcast for convenient understanding

- Global attainment for your research

- Manuscript accessibility in different formats

( Pdf, E-pub, Full Text, Audio)

- Unceasing customer service

Track the below URL for one-step submission https://juniperpublishers.com/online-submission.php 